Published in final edited form as:

Pediatr Nephrol. 2013 October ; 28(10): . doi:10.1007/s00467-013-2514-8.

\title{
Midaortic Syndrome: 30 Year Experience with Medical, Endovascular and Surgical Management
}

\author{
Diego Porras ${ }^{1}$, Deborah R. Stein ${ }^{2}$, Michael A. Ferguson ${ }^{2}$, Gulraiz Chaudry ${ }^{3}$, Ahmad \\ Alomari $^{3}$, Khashayar Vakili ${ }^{4}$, Steven J. Fishman ${ }^{4}$, James E. Lock ${ }^{1}$, and Heung B. Kim ${ }^{4}$ \\ ${ }^{1}$ Department of Cardiology, Boston Children's Hospital and Harvard Medical School, Boston, \\ Massachusetts \\ ${ }^{2}$ Division of Nephrology, Boston Children's Hospital and Harvard Medical School, Boston, \\ Massachusetts \\ ${ }^{3}$ Division of Interventional Radiology, Boston Children's Hospital and Harvard Medical School, \\ Boston, Massachusetts \\ ${ }^{4}$ Department of Surgery, Boston Children's Hospital and Harvard Medical School, Boston, \\ Massachusetts
}

\begin{abstract}
Background-Midaortic syndrome is often associated with refractory hypertension. Our aim was to better understand the short and medium-term outcomes in this patient population utilizing a multidisciplinary management approach.
\end{abstract}

Methods-We conducted a review of patients with midaortic syndrome treated at our institution over the past 30 years.

Results-Fifty-three patients presented at a median age of 6.7 (birth - 28.7) years. Thirty-five patients (66\%) underwent invasive management (percutaneous techniques: 21; surgical techniques: 5; both: 9). Percutaneous interventions were acutely successful in decreasing the gradient across the obstruction and degree of luminal stenosis. However, freedom from reintervention was 58\% at 1 year and $33 \%$ at 5 years. Freedom from reintervention after a surgical procedure was longer: $83 \%$ at 1 year and $72 \%$ at 10 years. At most recent follow-up, the majority of patients $(69 \%)$ were normotensive. The median duration between time of presentation and achievement of blood pressure control was $5.7(0.4-21.1)$ years. The median number of antihypertensive medications was $1(0-5)$.

Conclusions-A multidisciplinary management strategy, which couples comprehensive medical management with catheter-based and surgical interventions, can lead to adequate blood pressure control and preservation of end-organ function in patients with midaortic syndrome.

\section{Keywords}

midaortic syndrome; hypertension; renal artery stenosis; atypical coarctation of the aorta; abdominal coarctation; middle aortic syndrome

Address correspondence to: Diego Porras, Department of Cardiology, Boston Children's Hospital, 300 Longwood Avenue, Boston, MA 02115, 617-355-1491. 


\section{Introduction}

Narrowing of the abdominal aorta was first described by Quain in 1848[1], but the term middle-aortic syndrome was originally used by Sen et. al.,[2] in a report of 16 patients with inflammatory disease, resulting in stenosis in the midaorta (between the arch and the bifurcation). Currently, the term midaortic syndrome (MAS) is used for obstructive lesions of the midaorta, regardless of etiology. The disease commonly involves renal (>80\%) and splanchnic (50-70\%) branches of the aorta [3,4], and is the most common clinical syndrome associated with stenotic aorto-arteriopathy in children.[5]

Severe MAS is associated with significant morbidity and mortality. Hypertensive encephalopathy, congestive heart failure, and stroke develop in the third or fourth decade in almost 50\% of untreated MAS patients, with less than $20 \%$ survival reported after age 40 years. [6-8] Medical management of renovascular HTN caused by MAS has been largely unsuccessful, [5, 9] and invasive intervention is often required in order to achieve adequate blood pressure (BP) control, relieve symptoms, and reverse or prevent end-organ damage. Surgical results are varied, and range from an absence of surgical mortality with good longterm results to significant operative mortality.[4, 10-16] Balloon angioplasty and stenting as a palliative option to avoid surgery on the developing aorta has been described.[17-22] Most reports show encouraging results, though limitations include technical failures, [17, 18] iatrogenic tears and dissections,[18-20, 22] aneurysms,[22] and restenoses.[18]

Our aim was to review our experience in treating patients with MAS using medical, endovascular, and surgical methods, in an attempt to better understand the short and medium-term outcomes in this complex population.

\section{Methods}

Patients were identified through a search of departmental databases at Boston Children's Hospital. The Boston Children's Hospital Committee on Clinical Investigation approved this study.

Patients were divided into two groups according to the strategy used for management of anatomic disease: the invasive management group underwent catheter- and/or surgical-based interventions; the non-invasive management group underwent expectant care.

Data were obtained by retrospective chart review, with special attention paid to the following time points: (1) presentation; (2) mid-term follow up, defined as 3 months to 2 years after presentation (preference was given to notes written 1 year after presentation, if available); and (3) most recent follow-up. Hypertension severity was assessed using BP measurements recorded in nephrology or cardiology clinic notes. Definitions of systolic HTN were based on published standards by age. [23-25] For patients under 1 year of age, HTN was defined as a systolic BP $\geq 95^{\text {th }} \%$ for age. Stage II HTN was defined as a systolic BP $\geq 5 \mathrm{mmHg}$ above the $99^{\text {th }} \%$ for age. For patients between 1 and 17 years of age, HTN was defined as a systolic BP $\geq 95^{\text {th }} \%$ for age, gender, and height percentile and stage II HTN was considered to be present if the systolic BP was $\geq 5 \mathrm{mmHg}$ above the $99^{\text {th }} \%$ for age, gender, and height percentile. For patients over 17 years of age HTN was defined as a systolic BP $\geq 140 \mathrm{mmHg}$ and stage II HTN as a systolic BP $\geq 160 \mathrm{mmHg}$. Stage I HTN was defined at all ages as HTN under the age-specific cut-off for stage II HTN.

The estimated glomerular filtration rate (eGFR) at last follow up was calculated using the Schwartz formula. [26] Patients were classified as having normal eGFR or chronic kidney disease (CKD). Those classified as having CKD were further characterized as having stage 
II (eGFR $\left.60-89 \mathrm{ml} / \mathrm{min} / 1.73 \mathrm{~m}^{2}\right)$, stage III $\left(30-59 \mathrm{ml} / \mathrm{min} / 1.73 \mathrm{~m}^{2}\right)$, stage IV $(15-29 \mathrm{ml} /$ $\mathrm{min} / 1.73 \mathrm{~m}^{2}$ ), or stage V CKD (eGFR $\left.<15 \mathrm{ml} / \mathrm{min} / 1.73 \mathrm{~m}^{2}\right)$.[27]

The anatomic type of MAS was classified according to the most proximal site of anatomic obstruction: [4] Suprarenal (begins above the celiac artery or superior mesenteric artery), Intrarenal (begins at or above the renal arteries, but below the superior mesenteric artery), or Infrarenal (begins below the renal arteries). Using available imaging studies, the vessels involved in each patient were characterized. The percent stenosis of the mid-aorta was calculated using the narrowest luminal diameter and the luminal diameter of the aorta proximal to the obstruction (reference vessel diameter) in the following equation:

$\overline{\text { reference vessel diameter }}$

The $\%$ stenosis of the renal arteries was calculated in a similar fashion, with the exception that the reference vessel diameter for the renal arteries was the diameter of the renal artery distal to the obstruction and any post-stenotic dilation.

Percutaneous balloon angioplasty and stenting was performed using previously reported techniques. [22, 28] Stent placement was considered for residual significant stenosis (therapeutic stent) or vascular trauma (salvage stent). A single investigator measured lumen diameter before and after intervention.

Surgical interventions were performed using previously reported techniques.[4, 10, 12, 13, 29] Operative reports were reviewed and the procedure and technical details recorded, as well as complications or subsequent unplanned interventions.

\section{Statistical Analysis}

Data are presented as mean $\pm \mathrm{SD}$ or median (range), as appropriate. For comparison of variables between groups, Wilcoxon Rank Sum test was used for non-parametric nominal data and Fisher's exact test was used for ordinal data. Comparison of pre- and postprocedure gradients, lumen diameters and eGFR were performed using the Wilcoxon SignRanked test. A p-value $<0.05$ was considered statistically significant. Kaplan-Meier analysis was used to characterize freedom from surgical intervention, freedom from reintervention and freedom from reoperation. Log-rank test was used to compare survival functions between groups.

\section{Results}

\section{Patient Characteristics}

Fifty-three patients with MAS were managed at our center between 1981 and 2012. Nine patients were previously reported.[22, 30] Table 1 summarizes their clinical characteristics and provides a comparison between the two management groups. Patients in the invasive management group presented at an earlier age and had more severe disease, based on anatomical variables (higher \% stenosis of the mid aorta and larger proportion of patients with branches of the abdominal aorta with high grade stenosis or complete occlusion) and number of anti-HTN medications at last follow-up (Table 1).

\section{Age at Presentation}

The majority of patients were diagnosed with MAS before age 18 years, with the exception of three patients presenting between 20 and 27 years of age. Patients presenting before 1 year of age had more severe disease. Although the degree of stenosis of the mid-aorta was not higher in the younger patients, these patients had a greater number of branches with 
high-grade stenosis and more frequently had evidence of end-organ damage at presentation (Table 2).

\section{End-Organ Function}

Left Ventricular Function and Hypertrophy-Echocardiographic findings at presentation and last follow-up are summarized in Table 1. Of 22 patients with LVH at presentation, $13(59 \%)$ had resolution during the follow-up period (median duration to resolution: $2.5(0.9-26.4)$ years). Five patients presented with LV dysfunction, all of whom recovered function completely within the follow up period (median duration to recovery: 3.3 years ( 9 days -5.3 years)).

Renal Function-Two patients had documented end stage renal disease during the followup period. The etiology of renal failure in both patients was thought to be significantly compromised renal blood flow. Both presented in the neonatal period with acute renal insufficiency, one with severe bilateral renal artery stenosis and the other with no identifiable renal arteries, with renal arterial flow supplied through collateral vessels.

Twelve patients (23\%) had CKD at last follow-up: nine with CKD stage II and three with CKD stage III. Eight of these 12 patients $(75 \%)$ were $\geq 15$ years-old. The etiology of CKD was thought to be chronic renal ischemia. Three patients (all with CKD stage III) had an acute deterioration in already compromised renal function following initiation of angiotensin-converting enzyme inhibitors or angiotensin receptor blockers. There were no other identifiable risk factors for CKD in this small cohort. Factors that were tested included age at presentation, age at last follow up, presentation before 1 year of age, management group, associated diagnoses, history of catheterization, severe renal artery stenosis, severe bilateral renal artery stenosis, \% stenosis of the mid-aorta at presentation and at latest follow-up.

\section{Associated Diagnoses}

The majority of patients (64\%) had an associated diagnosis, including Williams syndrome (23\%), Takayasu's arteritis (15\%), Neurofibromatosis-1 (NF-1)(9\%), Allagile syndrome (7\%), and Moya-Moya disease (4\%). Less-common associated diagnoses were congenital rubella syndrome, epidermal nevus syndrome, and autosomal dominant supravalvar aortic stenosis syndrome, each affecting a single patient.

Supravalvar aortic stenosis was seen in 5 patients (9\%), one with autosomal dominant supravalvar aortic stenosis and 4 with Williams syndrome. Supravalvar pulmonary stenosis was seen in 2 patients with Williams syndrome. Peripheral pulmonary artery stenosis was seen in 11 patients $(21 \%), 5$ with Williams syndrome, 1 with autosomal dominant supravalvar aortic stenosis, 3 with Allagile syndrome, 1 with Moya-Moya disease and 1 with no known associated diagnosis.

\section{Anatomic Characteristics}

The most common anatomic type of MAS was suprarenal (60\%), followed by intrarenal (25\%) and infrarenal (15\%). In all patients obstruction consisted of one contiguous segment of stenotic aorta. The median percent stenosis of the midaorta at presentation for the cohort was $48(13-100) \%$. The median length of aorta involved was $4.6 \mathrm{~cm}(1-14 \mathrm{~cm})$. Other important anatomic characteristics of the cohort are summarized in Table 1. Involvement of at least one branch of the abdominal aorta was seen in in $85 \%$ of patients, and $15 \%$ of patients had complete obstruction of at least one branch of the abdominal aorta. The most common branches of the abdominal aorta involved were the renal arteries (69\%), followed by the celiac artery $(60 \%)$ and the superior mesenteric artery $(60 \%)$. The inferior mesenteric 
artery was not affected in any of the patients in this cohort, and generally showed compensatory enlargement.

\section{Hypertension Management}

All patients had HTN at the time of diagnosis, with the exception of 3 patients in whom midaortic obstruction was an incidental finding on imaging studies performed for other indications. One of these 3 patients subsequently developed HTN during follow-up; thus, $51 / 53(96 \%)$ patients in the cohort required management of HTN. Figure 1 summarizes the outcomes of HTN management. All patients with HTN $(n=51)$ showed improvement in blood pressure. Two patients had stage II HTN at last follow-up. Sixty-nine percent of the patients managed for HTN were normotensive at latest follow-up (14\% without antihypertensive medications). The median duration from the time of presentation to achievement of normal BP was 5.7 years $(0.4-21.1$ years $)$.

The median number of HTN medications at last follow-up was higher in the invasive management group (Table 1). The most commonly used medications for HTN were: calcium channel blockers (59\%), beta-blockers (56\%), and angiotensin-converting enzyme inhibitors (54\%). The medications most commonly used as single agents were beta-blockers (52\%), calcium channel blockers (24\%) and angiotensin-converting enzyme inhibitors (24\%). Other classes of drugs used included diuretics, clonidine, angiotensin receptor blockers, minoxidil and hydralazine. Clonidine was only used in regimens of $\geq 3$ medications, and minoxidil was only used in regimens of $\geq 5$ medications.

Although patients managed invasively more commonly had stage II HTN at presentation (67\% vs. $32 \%, \mathrm{p}=0.02)$, at most recent follow-up there was no difference between the two groups in regards to the proportion of patients with HTN, proportion of patients with stage II HTN, or mmHg above the age specific threshold for systolic HTN.

\section{Invasive Management}

Thirty-five patients underwent invasive management, including percutaneous techniques $(n=21)$ (Figure 2), surgery $(n=5)$ or both $(n=9)$ (Figure 3$)$. The median age at initial intervention was 4.9 years $(0.2-29.8$ years) and weight was $20.5 \mathrm{Kg}(2.5-73.5 \mathrm{Kg})$. Twentyseven of these patients underwent invasive procedures on the mid-aorta and in 8 patients the invasive strategies were focused on branches of the abdominal aorta. Patients that underwent invasive procedures on the midaorta had a median \% stenosis of $63 \%(40-100 \%)$, significantly higher than patients that did not undergo invasive procedures on the mid-aorta (35\% (13-58\%); $\mathrm{p}<0.001)$. All patients in the cohort with midaorta obstruction $\geq 60 \%$ underwent invasive management of the midaorta. No patient with midaorta obstruction < $40 \%$ underwent invasive management of the mid aorta. There were 16 patients with midaortic obstruction between 40 and 59\%, of which 7 (44\%) underwent invasive management of the mid-aorta and $9(56 \%)$ did not.

Percutaneous Interventions-Thirty patients underwent a total of 59 percutaneous interventions. In total, 51 vessels were balloon dilated and 25 were stented with a total of 57 stents. Percutaneous interventions included the midaorta in 21 of these patients (72\%): six patients had balloon dilation alone, and 15 underwent stent placement (therapeutic in 13 and salvage in 2). Percutaneous interventions on the midaorta were acutely successful in relieving obstruction (median gradient from $50(15-130) \mathrm{mmHg}$ to $22(0-60) \mathrm{mmHg}$; $\mathrm{p}<0.001)$ and decreasing the degree of stenosis (median \% stenosis from $52(25-100)$ to 15 $(-36-64) ; \mathrm{p}<0.001)$. 
Interventions on the renal arteries were performed in 12 patients (23\%). A total of 21 angioplasties were performed in 15 renal arteries. Stents were used in 7 of 15 vessels (therapeutic in 4 and salvage in 3). Percutaneous interventions were acutely successful in decreasing the degree of stenosis (median \% stenosis from $62(38-88)$ to $16(25-56)$; $\mathrm{p}<0.001$ ), and $86 \%$ of the intervened renal arteries had less than $30 \%$ stenosis after intervention.

There were 16 complications in 59 catheterization procedures (27\%) (Table 3). There was one procedure-related death (described below). The diagnosis of NF-1 was found to be a risk factor for vascular complications from catheter-based interventions $(\mathrm{p}=0.05)$. All 4 patients with NF-1 who underwent a percutaneous intervention had a vascular complication (2 patients had aneurysms found on follow-up at the site of prior angioplasty and 2 patients had vascular tears). Of the 5 patients with Takayasu's disease that underwent percutaneous transcatheter interventions, 3 had vascular complications ( 2 vascular tears and 1 aneurysm found on follow-up at the site of prior angioplasty), but this did not reach statistical significance as a risk factor for vascular complications $(\mathrm{p}=0.5)$. Of the 5 patients with Takayasu's disease, only 1 had documented elevated inflammatory markers at the time of intervention and that patient had a vascular tear after balloon angioplasty of the aorta. No other associated diagnosis was found to be a risk factor for vascular complications. Younger age at the time of intervention was also found to be a risk factor for vascular complication. Patients that had a vascular complication had a median age at intervention of $3.9(0.2$ to 22.2) years, compared to 10.5 ( 0.6 to 29.8 years) for those that did not have vascular complication $(\mathrm{p}=0.04)$.

There were no patients reported to have contrast induced nephropathy or clinically significant worsening of renal function after a catheterization procedure. Renal protection protocols that included peri-procedure administration of intravenous sodium bicarbonate and intravenous hydration were used in $17 / 59$ cases (28\%). The mean volume of contrast administered per procedure was $4.3 \pm 2.2 \mathrm{cc} / \mathrm{kg}$. Creatinine measurements before and after catheterization were only performed in patients with renal insufficiency or thought to be at particular risk for renal insufficiency. Of the 22 procedures with such data, there was no statistically significant difference between the pre- and post-procedure eGFR: median of 85 $(6-194)$ vs. $82(6-194) \mathrm{ml} / \mathrm{min} / 1.73 \mathrm{~m}^{2}$, respectively ( $\left.\mathrm{p}=0.53\right)$. The eGRF decreased by > $10 \%$ in two patients and it did not prolong hospitalization or change the management of either patient. There were two patients that had an increase of $>10 \%$ in eGFR after successful angioplasty of bilateral severe or complete obstruction of the renal arteries.

Surgical Procedures-Fourteen of the 35 patients (40\%) managed invasively underwent 22 surgical procedures. The median age at first surgical intervention was 6.1 years $(2-22.6$ years) and the median weight was $27.6 \mathrm{Kg}(10.2-61.5 \mathrm{Kg})$. Five patients $(36 \%)$ had at least one prior catheter-based intervention (median of $4(1-7)$ interventions).

Surgical procedures on the midaorta included: aorto-aortic bypass ( $\mathrm{n}=7$ )(Figure 3$)$, patch aortoplasty $(n=3)$, and primary aortic repair after aortic lengthening $(n=2)$. The surgical procedure included intervention on the renal or splanchnic arteries in 8 of these 12 patients and renal auto transplantation was the primary procedure in 2 additional patients.

There were 5 complications that required an unplanned surgical reintervention in 22 procedures $(23 \%)$, including bleeding $(n=1)$, thrombosis $(n=2)$, and dislodgement of a tissue expander $(\mathrm{n}=2)$. There were no surgery-related deaths. 


\section{Reinterventions}

Twenty-three (66\%) patients in the invasive management group underwent a total of 51 reinterventions (median of 2 per patient $(1-7$ reinterventions)). Freedom from any reintervention was 58\% at 1 year and 33\% at 5 years (Figure $4 a$ ). Freedom from reintervention was shorter for patients who presented before 1 year of age (freedom from reintervention at 1 year $47 \%$ vs. $62 \%$ for patients presenting $\geq 1$ year of age; $p=0.03$ ). The freedom from any reintervention after surgery was $83 \%$ at 1 year and $72 \%$ at 10 years (Figure 4b).

\section{Aneurysms}

Aneurysms in the midaorta or its branches were seen in 11 patients (21\%). Follow-up imaging was available in 7 of the 11 patients, at a median of 7 years ( 3 months to 8.5 years). No aneurysm had increased significantly in size and no complications were reported. The majority occurred at the site of prior angioplasty (73\%)(Table 3). However, three patients had four spontaneous aneurysms. One patient with renal artery stenosis and a spontaneous aneurysm underwent renal autotransplantation. In three patients the aneurysms were managed with percutaneous strategies (Table 3). Management was limited to observation in 7 patients. The only associated diagnosis seen in more than one patient with aneurysm(s) was NF-1 ( $\mathrm{n}=3$, one spontaneous and 2 after angioplasty).

\section{Neurovascular involvement}

Fifteen patients (28\%) underwent neurovascular imaging. The indication was neurologic symptoms in 10 patients, whereas in 5 patients imaging was carried out as part of a general evaluation of vasculopathy. Seven of the 10 patients undergoing neurovascular imaging due to symptoms were found to have vascular abnormalities. The most commonly seen abnormalities were occlusion or marked narrowing of intracranial vessels with distal reconstitution by collateral circulation, as can be seen in patients with Moya Moya syndrome ( 2 had a diagnosis of Moya Moya disease, 1 Allagile syndrome, 1 epidermal nevus syndrome, and 1 Takayasu's disease). One patient with NF-1 had an aneurysm of the anterior communicating artery, and one patient with idiopathic MAS had diffuse abnormalities, with multiple aneurysms and areas of discrete stenosis. None of the 5 asymptomatic patients were found to have vascular abnormalities.

\section{Survival}

There were 3 deaths $(6 \%)$ in the cohort during a median follow up period of 6.6 years $(0.1-$ 32 years). One patient was a 2 month-old premature infant, with a contained tear after cutting-balloon angioplasty of the left renal artery who died 6 days later after an acute deterioration secondary to a retroperitoneal bleed. Another patient was a 12 year-old girl with Williams syndrome who died 4 days after surgical repair of severe supravalvar aortic stenosis. The third patient was a 31 year-old man who died after prolonged hospitalization for heart failure due to severe aortic regurgitation. Survival for the entire cohort was $96 \%$ at 1 year and $90 \%$ at 15 years (Figure $4 \mathrm{c}$ ).

\section{Era Effect}

To evaluate for era effect, patients were divided into two groups based on whether they presented during the first $(n=14)$ or second $(n=39)$ half of the reported experience. Patients who presented after 1996 underwent intervention at an earlier age $(4.3(0.2-18.8)$ years vs. $12.7((2-29.8)$ years; $\mathrm{p}=0.01)$. There was no difference between the groups in regards to age at presentation, proportion of patients undergoing invasive management or surgery, or proportion who died during follow up. There were also technological and technical advances made during the reported experience that have changed the anatomic management of these 
patients. For example, cutting balloons and the surgical technique of primary aortic repair after aortic lengthening[29] were only available in the second half of the experience.

\section{Discussion}

Management of MAS is complex, requiring a multi-disciplinary approach. We provide a comprehensive description of our 30-year experience. Our data suggest a combination of medical management and invasive strategies can result in adequate control of HTN and preservation of end-organ function, even in patients with severe MAS and those who present at an early age.

Data regarding the natural history of MAS are limited to early reports. Two series reported in the 1960 s found that 30 to $45 \%$ of patients died before age 34 years, $[7,8]$ and in another series published in 1979, 55\% of untreated patients died at a mean age of 34 years[6]. Because ours is a relatively young cohort, it is impossible to make inferences regarding improvement in survival with the strategies described.

\section{Associated diagnoses}

The frequency of associated underlying diagnoses (64\%) underscores the heterogeneity in this patient population. When comparing results of different series in the literature, it is important to consider the associated diagnoses as well as the age at presentation of the patients in each series. For example, we found that patients presenting before age 1 year had more severe disease. Our series is almost exclusively composed of patients presenting during childhood. Many series in the literature are predominantly composed of adults, and therefore may represent a different spectrum of disease. Also, diagnoses like Takayasu's arteritis will be more prevalent in adult series or in certain geographical areas.

Multiple heterogeneous conditions are often grouped together under one diagnosis of MAS. Although they may share a similar vascular phenotype, it is important to keep in mind that the underlying or associated diagnoses may play a role in the pathophysiology, natural history, prognosis, and response to therapy. For example, we found that the diagnosis of NF-1 was a risk factor for vascular complications of endovascular interventions. Patients with NF-1 are known to have a predisposition to develop spontaneous aneurysms [31-34], and there may be arterial wall abnormalities in these patients that place them at increased risk for vascular complications after endovascular interventions. Similarly, patients with active vascular inflammation at the time of intervention may be at higher risk for vascular complications, and controlling the inflammatory process before intervening is preferable. As we continue to learn more about each specific etiology of MAS, we will be better equipped to develop specific management strategies to optimally approach each diagnosis.

\section{End-organ Function}

LVH can be used as a marker of hypertensive end-organ damage,[35] and has been shown to have prognostic implications in hypertensive adults.[36-38] LVH was relatively common in this cohort and resolved in the majority of the patients, although this resolution took several years (median > 2 years). Advanced CKD, on the other hand was rare in our series. However, mild to moderate decreases in eGFR at last follow up were relatively common. This finding is consistent with other reports.[39] Although this level of renal compromise is rarely clinically significant, it may progress and become an important source of morbidity. Although we did not find any cases of clinically significant contrast-related nephrotoxicity after endovascular procedures in this series, we consider all patients with MAS to be at high risk for contrast-induced nephrotoxicity and take every precaution to prevent this complication. 
Neurovascular involvement in patients with MAS has been described. [3, 6, 40, 41] We found 7 patients with neurovascular abnormalities in our series (13\%). However, routine screening for neurovascular abnormalities was not carried out, so it is possible that these abnormalities were underdiagnosed. Importantly, we found that 7 of 10 patients with neurologic symptoms had abnormal findings on neuroimaging, whereas none of the 5 asymptomatic patients had abnormal findings. Early diagnosis of a neurovascular abnormality in patients with MAS is very important and may affect their management. However, based on our findings, the yield of universal screening remains questionable. Therefore, we continue to perform screening for neurovascular abnormalities based on clinical findings and the particular associated diagnoses.

\section{Anatomic Characteristics}

Several classifications have been proposed to describe the anatomic characteristics of MAS. $[3,4,6,14]$ The majority focus on the most proximal site of stenosis. However, we find the most proximal site of stenosis to be only partially informative. We prefer a more descriptive approach, including: site of most proximal involvement, \% stenosis and length of midaorta involved, branches involved, branches with high grade stenosis, and branches with complete obstruction. We also give consideration to the pressure gradient across the area of obstruction. However, we have found that in patients with well- developed collateral circulation, the pressure gradient may be low or absent, despite the presence of severe midaortic obstruction.

\section{Invasive Management}

Patients managed invasively had more severe disease at presentation, from both an anatomic and functional perspectives. Importantly, at last follow-up, there was no difference between the two groups in regards to the severity of HTN, degree of stenosis of the mid-aorta, or endorgan function. These findings suggest that the invasive management strategies not only improved the anatomical substrate of the patients, but were an important adjunct to medical therapy in patients with severe MAS, allowing for improved control of blood pressure, as well as recovery and/or preservation of end organ function.

When considering indications for invasive management in patients with MAS, there are no accepted guidelines. Multiple factors need to be considered, and the anatomic substrate is only one of them. Based on our data, patients with midaortic stenosis $260 \%$ are highly likely to require invasive management, whereas patients with stenosis $<40 \%$ are unlikely to require such management for midaortic obstruction. Even if the degree of stenosis of the midaorta is mild, invasive management of severe branch stenoses may be required. Other factors to consider include: HTN refractory to medical management or significant side effects from antihypertensive medications, evidence of end-organ damage despite medical management of hypertension, and significant symptoms like claudication or abdominal angina. This approach is similar to that advocated by other authors.[39, 42]

Percutaneous interventions on the mid aorta were effective in relieving obstruction in the acute setting. However, as has been reported by other investigators, there was a high incidence of restenosis and reintervention.[5, 21, 22, 43] The mechanisms of reobstruction remain poorly understood and are the subject of ongoing research by our group. In the case of restenosis after stenting, the major mechanisms responsible appear to be in-stent stenosis, lack of growth of the stented area, and stenosis of the segment of aorta immediately distal and/or proximal to the stents.

As noted in other reports, percutaneous interventions can be associated with severe complications, including vascular tears, development of aneurysms at sites of prior 
angioplasty, and even death.[17-20,22] The importance of operator experience and expertise cannot be overstated. In addition to available surgical backup, the presence of at least two experienced operators for every procedure is recommended.

Surgical interventions were successful in relieving obstruction and resulted in a longer freedom from reintervention and fewer complications than catheter based interventions. The surgical approaches varied widely and there were too few patients to make inferences about a specific surgical technique. All patients who underwent surgical procedures had improvement of HTN, with over $2 / 3$ being normotensive at last follow-up (1/3 without antihypertensive medications). These results are consistent with other surgical series, which report improvement in BP in $83-100 \%$ of patients and normalization of BP in $50-94 \%$ of patients.[6, 11, 14, 15, 44]

Our general approach to patients with MAS has been to employ invasive measures when medical management is insufficient or there is impending end-organ damage. The choice of invasive strategy depends on the anatomy, patient age, and condition. We tend to favor early intervention, which often means using percutaneous techniques as palliative measures with the goal of allowing growth and preservation of end-organ function until the patient is of an age and size that is more amenable to definitive corrective surgery.

\section{Limitations}

There are several limitations to this study, which was retrospective, and thus has all the limitations inherent to such a design. Data availability was variable. Patients were not managed in a standardized fashion, making indications for intervention and/or reintervention non-uniform. Over half of the patients in the cohort were referred from other states, and therefore there may be a bias towards more severe disease.

\section{Conclusions}

In summary, patients with MAS present a complex array of challenges and can have significant morbidity and mortality associated with their disease. A multidisciplinary management strategy, which includes careful and comprehensive medical management coupled with catheter-based and surgical interventions, can lead to adequate BP control and preservation of end-organ function in this patient population.

\section{References}

1. Quain R. Partial Coarctation of the Abdominal Aorta. Trans Path Soc London. 1847; 1:244-246.

2. Sen PK, Kinare SG, Engineer SD, Parulkar GB. The Middle Aortic Syndrome. Br Heart J. 1963; 25:610-618. [PubMed: 14063008]

3. Hallett JW Jr. Brewster DC, Darling RC, O'Hara PJ. Coarctation of the abdominal aorta: current options in surgical management. Ann Surg. 1980; 191:430-437. [PubMed: 7369807]

4. Stanley JC, Criado E, Eliason JL, Upchurch GR Jr, Berguer R, Rectenwald JE. Abdominal aortic coarctation: surgical treatment of 53 patients with a thoracoabdominal bypass, patch aortoplasty, or interposition aortoaortic graft. J Vasc Surg. 2008; 48:1073-1082. [PubMed: 18692352]

5. D’Souza SJ, Tsai WS, Silver MM, Chait P, Benson LN, Silverman E, Hebert D, Balfe JW. Diagnosis and management of stenotic aorto-arteriopathy in childhood. J Pediatr. 1998; 132:10161022. [PubMed: 9627596]

6. Graham LM, Zelenock GB, Erlandson EE, Coran AG, Lindenauer SM, Stanley JC. Abdominal aortic coarctation and segmental hypoplasia. Surgery. 1979; 86:519-529. [PubMed: 483161]

7. Onat T, Zeren E. Coarctation of the abdominal aorta. Review of 91 cases. Cardiologia. 1969; 54:140-157. [PubMed: 5372884]

8. Senning A, Johansson L. Coarctation of the abdominal aorta. J Thorac Cardiovasc Surg. 1960; 40:517-523. [PubMed: 13750113] 
9. Ellis D, Shapiro R, Scantlebury VP, Simmons R, Towbin R. Evaluation and management of bilateral renal artery stenosis in children: a case series and review. Pediatr Nephrol. 1995; 9:259267. [PubMed: 7632507]

10. Bergamini TM, Bernard JD, Mavroudis C, Backer CL, Muster AJ, Richardson JD. Coarctation of the abdominal aorta. Ann Vasc Surg. 1995; 9:352-356. [PubMed: 8527335]

11. De Bakey ME, Garrett HE, Howell JF, Morris GC. Coarctation of the abdominal aorta with renal arterial stenosis: Surgical considerations. Ann Surg. 1969; 165:830-843. [PubMed: 6023938]

12. Delis KT, Gloviczki P. Middle aortic syndrome: from presentation to contemporary open surgical and endovascular treatment. Perspect Vasc Surg Endovasc Ther. 2005; 17:187-203. [PubMed: $16273154]$

13. Giordano JM, Leavitt RY, Hoffman G, Fauci AS. Experience with surgical treatment of Takayasu's disease. Surgery. 1991; 109:252-258. [PubMed: 1672048]

14. Mickley V, Fleiter T. Coarctations of descending and abdominal aorta: long-term results of surgical therapy. J Vasc Surg. 1998; 28:206-214. [PubMed: 9719315]

15. Taketani T, Miyata T, Morota T, Takamoto S. Surgical treatment of atypical aortic coarctation complicating Takayasu's arteritis--experience with 33 cases over 44 years. J Vasc Surg. 2005; 41:597-601. [PubMed: 15874922]

16. O’Neill JA Jr, Berkowitz H, Fellows KJ, Harmon CM. Midaortic syndrome and hypertension in childhood. J Pediatr Surg. 1995; 30:164-171. discussion 171-162. [PubMed: 7738733]

17. Sharma S, Bahl VK, Saxena A, Kothari SS, Talwar KK, Rajani M. Stenosis in the aorta caused by non-specific aortitis: results of treatment by percutaneous stent placement. Clin Radiol. 1999; 54:46-50. [PubMed: 9915510]

18. Sharma S, Shrivastava S, Kothari SS, Kaul U, Rajani M. Influence of angiographic morphology on the acute and longer-term outcome of percutaneous transluminal angioplasty in patients with aortic stenosis due to nonspecific aortitis. Cardiovasc Intervent Radiol. 1994; 17:147-151. [PubMed: 7916266]

19. Fava MP, Foradori GB, Garcia CB, Cruz FO, Aguilar JG, Kramer AS, Valdes FE. Percutaneous transluminal angioplasty in patients with Takayasu arteritis: five-year experience. J Vasc Interv Radiol. 1993; 4:649-652. [PubMed: 8106024]

20. Rao SA, Mandalam KR, Rao VR, Gupta AK, Joseph S, Unni MN, Subramanyan R, Neelakandhan KS. Takayasu arteritis: initial and long-term follow-up in 16 patients after percutaneous transluminal angioplasty of the descending thoracic and abdominal aorta. Radiology. 1993; 189:173-179. [PubMed: 8103942]

21. Tyagi S, Kaul UA, Nair M, Sethi KK, Arora R, Khalilullah M. Balloon angioplasty of the aorta in Takayasu's arteritis: initial and long-term results. Am Heart J. 1992; 124:876-882. [PubMed: 1356310]

22. Siwik ES, Perry SB, Lock JE. Endovascular stent implantation in patients with stenotic aortoarteriopathies: early and medium-term results. Catheter Cardiovasc Interv. 2003; 59:380-386. [PubMed: 12822165]

23. The fourth report on the diagnosis, evaluation, and treatment of high blood pressure in children and adolescents. Pediatrics. 2004; 114:555-576. [PubMed: 15286277]

24. Dionne JM, Abitbol CL, Flynn JT. Hypertension in infancy: diagnosis, management and outcome. Pediatr Nephrol. 2012; 27:17-32. [PubMed: 21258818]

25. Whitworth JA. 2003 World Health Organization (WHO)/International Society of Hypertension (ISH) statement on management of hypertension. J Hypertens. 2003; 21:1983-1992. [PubMed: 14597836]

26. Schwartz GJ, Haycock GB, Edelmann CM Jr, Spitzer A. A simple estimate of glomerular filtration rate in children derived from body length and plasma creatinine. Pediatrics. 1976; 58:259-263. [PubMed: 951142]

27. Stevens LA, Coresh J, Greene T, Levey AS. Assessing kidney function--measured and estimated glomerular filtration rate. N Engl J Med. 2006; 354:2473-2483. [PubMed: 16760447]

28. Khan MS, Moore JW. Treatment of abdominal aortic pseudoaneurysm with covered stents in a pediatric patient. Catheter Cardiovasc Interv. 2000; 50:445-448. [PubMed: 10931619] 
29. Kim HB, Vakili K, Modi BP, Ferguson MA, Guillot AP, Potanos KM, Prabhu SP, Fishman SJ. A Novel Treatment for the Midaortic Syndrome. N Engl J Med. 2012; 367:2361-2362. [PubMed: 23234530]

30. Lillehei CW, Shamberger RC. Staged reconstruction for middle aortic syndrome. J Pediatr Surg. 2001; 36:1252-1254. [PubMed: 11479869]

31. Friedman JM, Arbiser J, Epstein JA, Gutmann DH, Huot SJ, Lin AE, McManus B, Korf BR. Cardiovascular disease in neurofibromatosis 1: report of the NF1 Cardiovascular Task Force. Genet Med. 2002; 4:105-111. [PubMed: 12180143]

32. Hamilton SJ, Friedman JM. Insights into the pathogenesis of neurofibromatosis 1 vasculopathy. Clin Genet. 2000; 58:341-344. [PubMed: 11140831]

33. Lin AE, Birch PH, Korf BR, Tenconi R, Niimura M, Poyhonen M, Armfield Uhas K, Sigorini M, Virdis R, Romano C, Bonioli E, Wolkenstein P, Pivnick EK, Lawrence M, Friedman JM. Cardiovascular malformations and other cardiovascular abnormalities in neurofibromatosis 1 . Am J Med Genet. 2000; 95:108-117. [PubMed: 11078559]

34. Oderich GS, Sullivan TM, Bower TC, Gloviczki P, Miller DV, Babovic-Vuksanovic D, Macedo TA, Stanson A. Vascular abnormalities in patients with neurofibromatosis syndrome type I: clinical spectrum, management, and results. J Vasc Surg. 2007; 46:475-484. [PubMed: 17681709]

35. Sorof JM, Cardwell G, Franco K, Portman RJ. Ambulatory blood pressure and left ventricular mass index in hypertensive children. Hypertension. 2002; 39:903-908. [PubMed: 11967247]

36. Levy D, Garrison RJ, Savage DD, Kannel WB, Castelli WP. Prognostic implications of echocardiographically determined left ventricular mass in the Framingham Heart Study. N Engl J Med. 1990; 322:1561-1566. [PubMed: 2139921]

37. Koren MJ, Devereux RB, Casale PN, Savage DD, Laragh JH. Relation of left ventricular mass and geometry to morbidity and mortality in uncomplicated essential hypertension. Ann Intern Med. 1991; 114:345-352. [PubMed: 1825164]

38. Brown DW, Giles WH, Croft JB. Left ventricular hypertrophy as a predictor of coronary heart disease mortality and the effect of hypertension. Am Heart J. 2000; 140:848-856. [PubMed: 11099987]

39. Tummolo A, Marks SD, Stadermann M, Roebuck DJ, McLaren CA, Hamilton G, Dillon MJ, Tullus K. Mid-aortic syndrome: long-term outcome of 36 children. Pediatr Nephrol. 2009; 24:2225-2232. [PubMed: 19603194]

40. Stanley JC, Graham LM, Whitehouse WM Jr, Zelenock GB, Erlandson EE, Cronenwett JL, Lindenauer SM. Developmental occlusive disease of the abdominal aorta and the splanchnic and renal arteries. Am J Surg. 1981; 142:190-196. [PubMed: 7258526]

41. Ishii K, Isono M, Kasai N, Nakano T, Kubo T, Inoue R, Nomura Y. Midaortic syndrome in childhood associated with a ruptured cerebral aneurysm: a case report. Surg Neurol. 2001; 55:209_ 212. [PubMed: 11358589]

42. Sethna CB, Kaplan BS, Cahill AM, Velazquez OC, Meyers KE. Idiopathic mid-aortic syndrome in children. Pediatr Nephrol. 2008; 23:1135-1142. [PubMed: 18320235]

43. Sharma S, Thatai D, Saxena A, Kothari SS, Guleria S, Rajani M. Renovascular hypertension resulting from nonspecific aortoarteritis in children: midterm results of percutaneous transluminal renal angioplasty and predictors of restenosis. Am J Roentgenol. 1996; 166:157-162. [PubMed: 8571868]

44. Messina LM, Reilly LM, Goldstone J, Ehrenfeld WK, Ferrell LD, Stoney RJ. Middle aortic syndrome. Effectiveness and durability of complex arterial revascularization techniques. Ann Surg. 1986; 204:331-339. [PubMed: 3753060] 


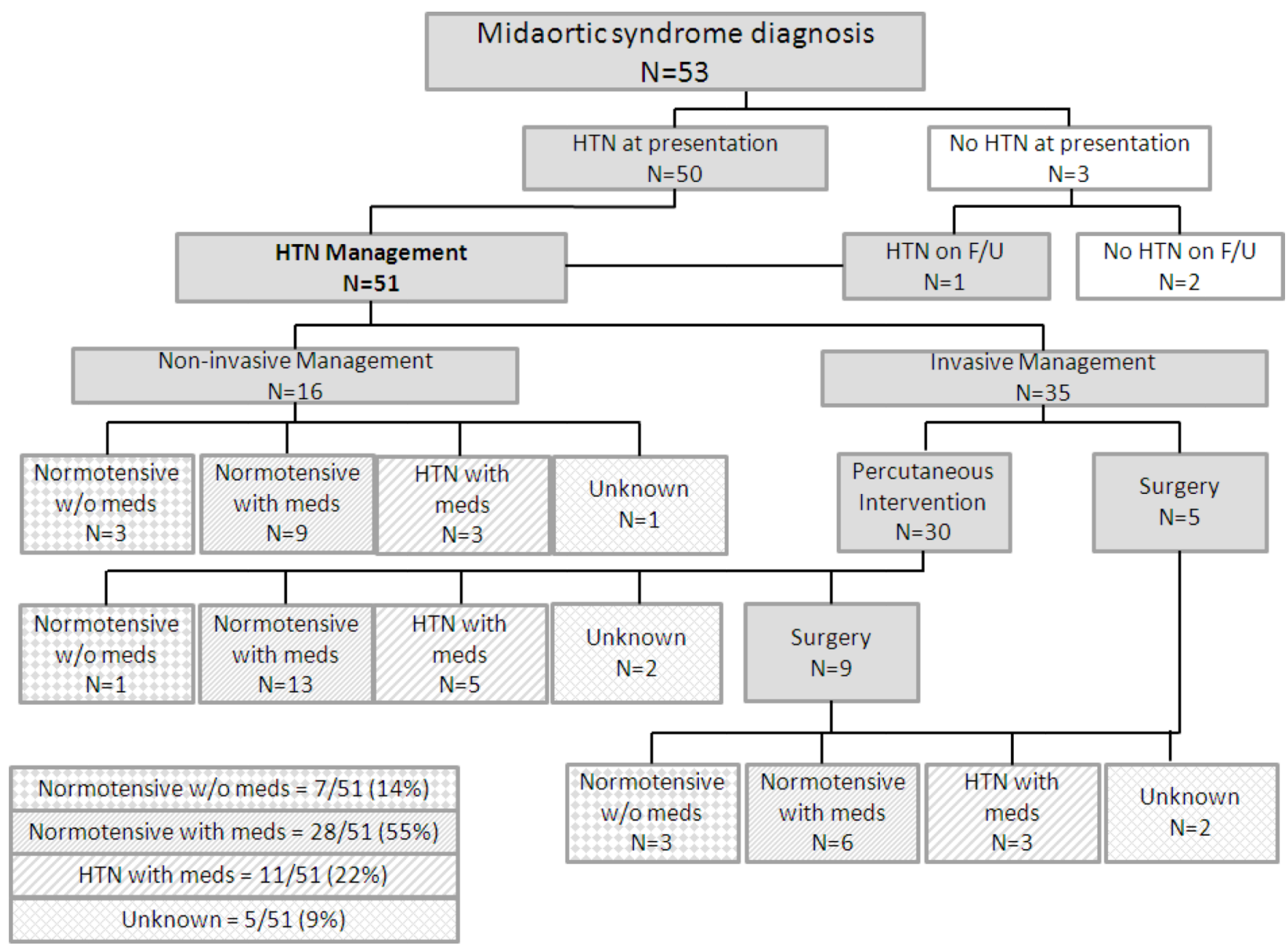

Figure 1.

Outcomes of Hypertension Management in patients with Midaortic Syndrome. F/U: followup; HTN: hypertension; Meds: anti-hypertensive medications; w/o: without. 

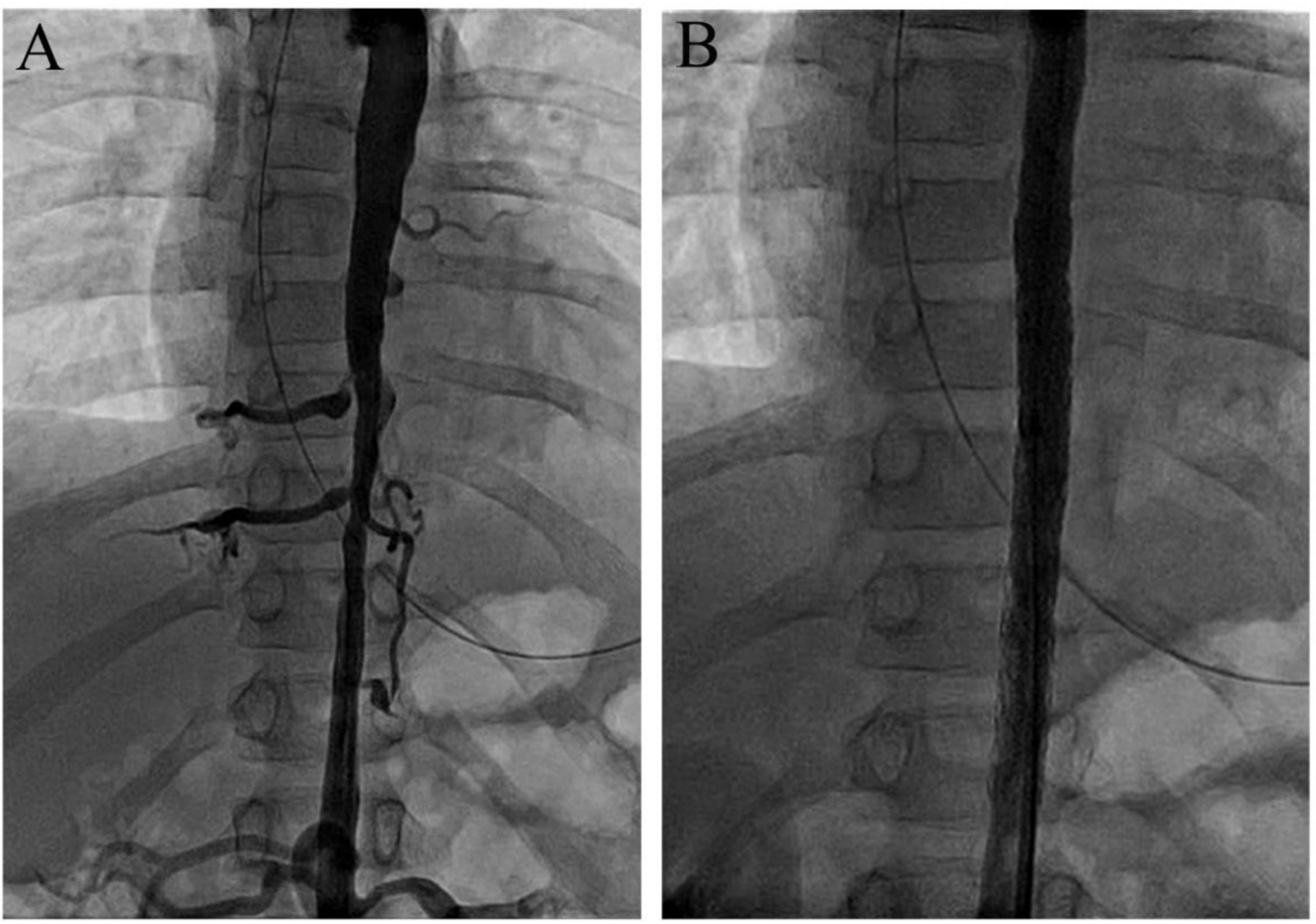

Figure 2.

Patient with midaortic syndrome managed with stenting of the midaorta. A. Frontal projection of angiogram showing long-segment narrowing in the distal thoracic and proximal abdominal aorta. B. Frontal projection of angiogram showing the midaorta after placement of stents, with complete resolution of the obstruction. 


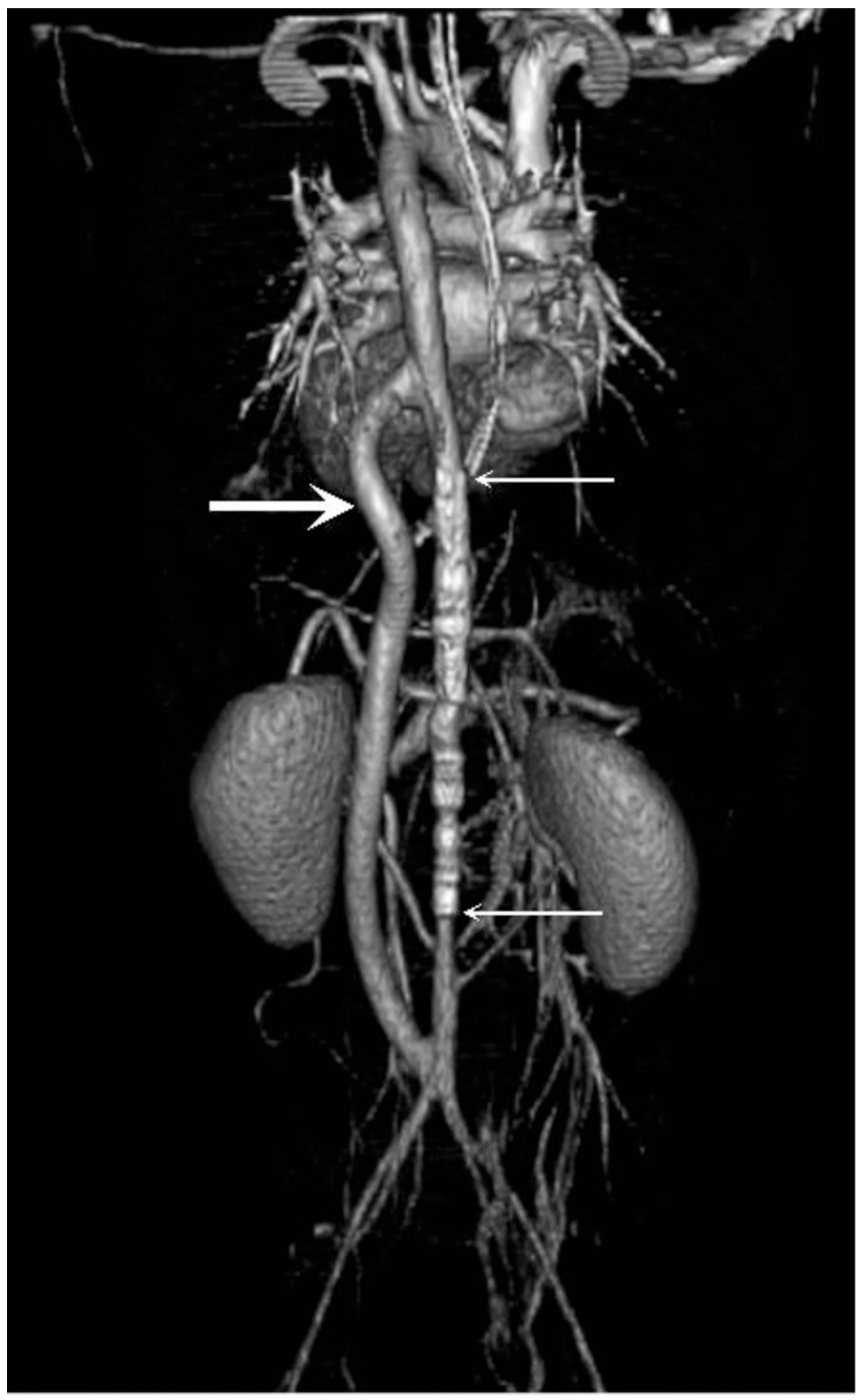

Figure 3.

Postero-anterior view of three dimensional CTA reconstruction in patient with midaortic syndrome managed with combination of endovascular and surgical techniques. Abdominal aorta was stented during early childhood (between small arrows). A synthetic graft (large arrow) was used to bypass the narrowed aortic segment after the child was almost fully grown. 

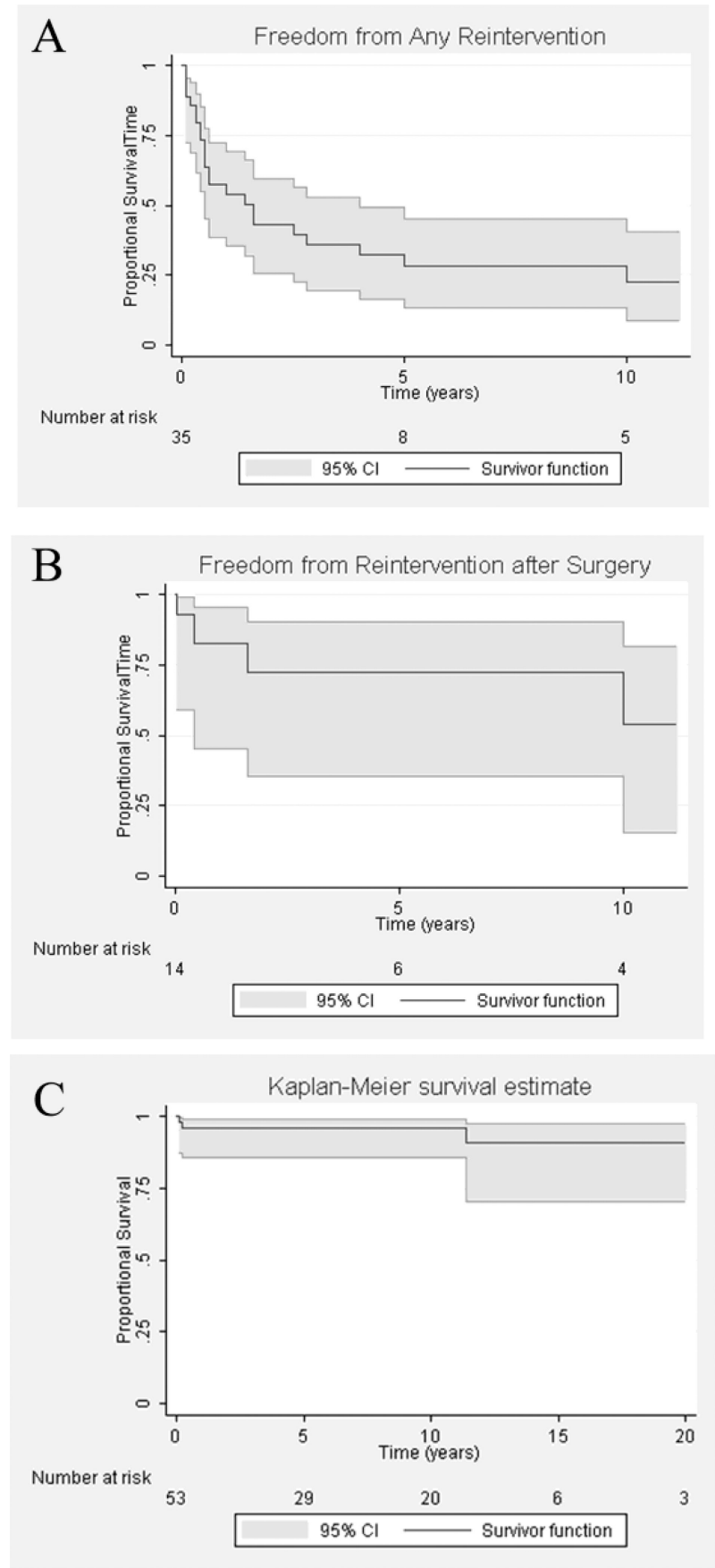

Figure 4.

Kaplan-Meier Curves Representing Survival Analysis. a. Freedom from any reintervention. b. Freedom from reintervention after surgery. c. Survival 
Table 1

Patient Characteristics

\begin{tabular}{|c|c|c|c|c|}
\hline Variable & $\begin{array}{l}\text { All patients } \\
(\mathbf{n}=53)\end{array}$ & $\begin{array}{l}\text { Non-invasive } \\
\text { management } \\
\text { group } \\
(n=18)\end{array}$ & $\begin{array}{l}\text { Invasive } \\
\text { management } \\
\text { group }(n=35)\end{array}$ & p value \\
\hline \multicolumn{5}{|l|}{ Demographics } \\
\hline Age at presentation (years) & $6.7(0-28.7)$ & $11.6(0.7-22.6)$ & $4.2(0-28.7)$ & 0.005 \\
\hline Gender (male) & $29(55 \%)$ & $13(72 \%)$ & $16(46 \%)$ & 0.09 \\
\hline \multicolumn{5}{|l|}{ Clinical Characteristics/Severity } \\
\hline \multicolumn{5}{|l|}{ Clinical findings at presentation } \\
\hline - HTN & $50(94 \%)$ & $15(83 \%)$ & $35(100 \%)$ & 0.04 \\
\hline - Claudication & $3(6 \%)$ & $1(6 \%)$ & $2(6 \%)$ & 1.0 \\
\hline - Abdominal complaints & $7(14 \%)$ & $3(21 \%)$ & $4(13 \%)$ & 0.7 \\
\hline - Failure to thrive & $1(2 \%)$ & $0(0 \%)$ & $1(3 \%)$ & 1.0 \\
\hline - Congestive heart failure & $5(10 \%)$ & $0(0 \%)$ & $5(14 \%)$ & 0.15 \\
\hline - Renal Insufficiency & $4(8 \%)$ & $0(0 \%)$ & $4(11 \%)$ & 0.3 \\
\hline Number of BP meds at last f/u & $1(0-5)$ & $1(0-3)$ & $2(0-5)$ & 0.04 \\
\hline Percent stenosis of midaorta at presentation & $48(13-100)(n=39)$ & $35(13-58)(\mathrm{n}=15)$ & $56(18-100)(\mathrm{n}=24)$ & 0.002 \\
\hline Percent stenosis of midaorta at last $\mathrm{f} / \mathrm{u}$ & $38(0-71)(n=32)$ & $41(20-71)(n=11)$ & $32(0-59)(n=21)$ & 0.23 \\
\hline Number of branches of abdominal aorta affected & $2(0-4)(n=48)$ & $2(0-4)(n=18)$ & $3(0-4)(n=30)$ & 0.6 \\
\hline High-grade bilateral renal artery stenosis & $17 / 48(35 \%)$ & $2 / 18(11 \%)$ & $15 / 30(50 \%)$ & 0.006 \\
\hline $\begin{array}{l}\text { Number of branches of abdominal aorta with high-grade } \\
\text { stenosis }\end{array}$ & $1(0-4)(n=48)$ & $0(0-4)(n=18)$ & $2(0-4)(n=30)$ & 0.02 \\
\hline Occluded branches of abdominal aorta & $7 / 48(15 \%)(\mathrm{n}=48)$ & $0 / 18(0 \%)(\mathrm{n}=18)$ & $7 / 30(23 \%)(\mathrm{n}=30)$ & 0.03 \\
\hline \multicolumn{5}{|l|}{ End-organ Indicators } \\
\hline \multicolumn{5}{|l|}{ LV size and function at presentation } \\
\hline$-\mathrm{LVH}$ & $22 / 45(49 \%)$ & $5 / 17(29 \%)$ & $17 / 28(61 \%)$ & 0.04 \\
\hline - LV mass z score & $2.2(-1.7-7.5)$ & $0.2(-1.7-7.5)$ & $3.4(0.3-7.4)$ & 0.02 \\
\hline - LV dysfunction & $5 / 46(11 \%)$ & $0 / 17(0 \%)$ & $5 / 29(22 \%)$ & 0.09 \\
\hline \multicolumn{5}{|l|}{ LV size and function at last $\mathrm{f} / \mathrm{u}$} \\
\hline$-\mathrm{LVH}$ & $10 / 43(23 \%)$ & $4 / 16(25 \%)$ & $6 / 27(22 \%)$ & 0.56 \\
\hline - LV mass z score & $0.7(-1.6-6.0)$ & $0.5(-0.95-5.4)$ & $0.8(-1.6-6.0)$ & 0.97 \\
\hline - LV dysfunction & $1 / 44(2 \%)$ & $1 / 18(6 \%)$ & $0 / 26(0 \%)$ & 0.41 \\
\hline eGFR at last follow-up & $108(45-248)(n=37)$ & $97(47-204)(n=13)$ & $111(45-248)(n=24)$ & 0.24 \\
\hline
\end{tabular}

Note: Denominator differences reflect number of patients for which data were available for each category. 
BP: blood pressure; f/u: follow-up; eGFR: estimated glomerular filtration rate; HTN: hypertension; LV: left ventricle; LVEF: left ventricular ejection fraction; LVH: left ventricular hypertrophy. Meds: medications. 
Table 2

Comparison of Markers of Severity of Disease by Age at Presentation

\begin{tabular}{|l|l|l|l|}
\hline Variable & $\begin{array}{l}<\mathbf{1} \text { year } \\
\text { old }(\mathbf{n = 1 1})\end{array}$ & $\begin{array}{l}\text { y year old } \\
(\mathbf{n = 4 2})\end{array}$ & p value \\
\hline Stage II HTN & $8 / 10(80 \%)$ & $17 / 36(47 \%)$ & 0.08 \\
\hline HTN Emergency & $4 / 11(36 \%)$ & $2 / 42(5 \%)$ & $\mathbf{0 . 0 1 3}$ \\
\hline LV dysfunction & $3 / 11(28 \%)$ & $2 / 42(5 \%)$ & 0.054 \\
\hline \# of anti-HTN medications at last follow up & $2(1-3)$ & $1(0-5)$ & 0.32 \\
\hline \% stenosis of mid-aorta at presentation & $41(17-81)$ & $46(13-86)$ & 0.97 \\
\hline \# of branches with severe stenosis & $3(0-4)$ & $1(0-4)$ & $\mathbf{0 . 0 2 6}$ \\
\hline LV mass z-score at presentation & $3.8(1.7-7.4)$ & $0.67(-1.7-7.5)$ & $\mathbf{0 . 0 4 9}$ \\
\hline Renal dysfunction at presentation & $3 / 11(27 \%)$ & $1 / 42(2 \%)$ & $\mathbf{0 . 0 2 5}$ \\
\hline
\end{tabular}

Note: Denominator differences reflect number of patients for which data were available for each category

HTN: hypertension; LV: left ventricle 
Table 3

Complications associated with catheterization procedures

\begin{tabular}{|l|l|l|l|}
\hline Complication & Number of patients & Management & Follow-up \\
\hline Mid-aorta vascular tear & 5 & Observation: 3 Rescue stent: 2 & 1 aneurysm noted on follow-up. Others stable. \\
\hline Renal artery vascular tear & 5 & Observation: 2 Rescue stent: 3 & $\begin{array}{l}\text { One death 6 days after procedure secondary } \\
\text { to acute retroperitoneal hemorrhage. Two } \\
\text { aneurysms noted on follow-up. Two other } \\
\text { patients stable. }\end{array}$ \\
\hline $\begin{array}{l}\text { Aneurysm at site of prior } \\
\text { angioplasty }\end{array}$ & $\begin{array}{l}8 \text { (including 3 mentioned } \\
\text { above) }\end{array}$ & $\begin{array}{l}\text { Observation: 5 Coil occlusion: } \\
\text { s Covered stent: 1 Bare metal } \\
\text { stent: 1 }\end{array}$ & $\begin{array}{l}\text { No reports of significant change in size or } \\
\text { complications on follow-up. }\end{array}$ \\
\hline Stent embolization & 1 & $\begin{array}{l}\text { Expansion of embolized stent } \\
\text { in distal abdominal aorta }\end{array}$ & $\begin{array}{l}\text { Stent in stable position, re-expanded at } \\
\text { subsequent catheterization. No complications } \\
\text { encountered on follow-up. }\end{array}$ \\
\hline
\end{tabular}

